\title{
CONF-970302--6
}

Note: This is a preprint of a paper being submitted for publication. Contents of this paper should not be quoted nor referred to without permission of the author(s).

97 spring MRS meeting.

\section{Enhanced Diffusion of Dopants in Vacancy Supersaturation Produced} by $\mathrm{MeV}$ Implantation

V. C. Venezia, T. E. Haynes, and A. Agarwal*

Oak Ridge National Laboratory

(*presently located at Bell Laboratory)

Oak Ridge, TN

\section{H. J. Gossman and D. J. Eaglesham}

Bell Laboratory

Murray Hill, NJ

"The submitted manuscript has been authored by a contractor of the U.S. Government under contract No. DE-AC05-96OR22464. Accordingly, the U.S. Government retains a nonexclusive, royalty-free license to publish or reproduce the published form of this contribution, or allow others to do so, for U.S. Government purposes."

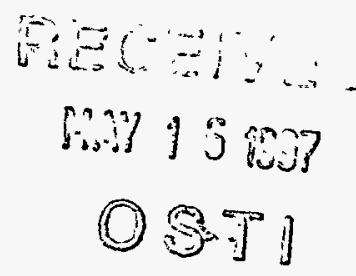

Prepared by the

Oak Ridge National Laboratory

Oak Ridge, Tennessee 37831

managed by

LOCKHEED MARTIN ENERGY RESEARRCH CORP.

for the

U.S. DEPARTMENT OF ENERGY

under contract DE-AC05-960R22464

April 1997 


\section{DISCLAIMER}

This report was prepared as an account of work sponsored by an agency of the United States Government. Neither the United States Government nor any agency thereof, nor any of their employees, make any warranty, express or implied, or assumes any legal liability or responsibility for the accuracy, completeness, or usefulness of any information, apparatus, product, or process disclosed, or represents that its use would not infringe privately owned rights. Reference herein to any specific commercial product, process, or service by trade name, trademark, manufacturer, or otherwise does not necessarily constitute or imply its endorsement, recommendation, or favoring by the United States Government or any agency thereof. The views and opinions of authors expressed herein do not necessarily state or reflect those of the United States Government or any agency thereof. 


\section{DISCLAMIER}

Portions of this document may be illegible in electronic image products. Images are produced from the best available original document. 


\author{
V.C. VENEZIA, ${ }^{a, b}$, T. E. HAYNES ${ }^{a}$, A. AGARWAL ${ }^{\mathrm{a}, \mathrm{c}}$, H. -J. GOSSMANN ${ }^{\mathrm{c}}$ and \\ D. J. EAGLESHAM ${ }^{\mathrm{c}}$ \\ ${ }^{a}$ Solid State Division, Oak Ridge National Laboratory, Oak Ridge, Tennessee 37831 USA \\ ${ }^{b}$ Department of Physics, University of North Texas, Denton, Texas 76201 USA \\ ${ }^{c}$ Bell Laboratory, Lucent Technologies, Murray Hill, New Jersey 07974 USA
}

\title{
ABSTRACT
}

The diffusion of $\mathrm{Sb}$ and $\mathrm{B}$ markers has been studied in vacancy supersaturations produced by $\mathrm{MeV}$ Si implantation in float zone (FZ) silicon and bonded etch-back silicon-oninsulator (BESOI) substrates. MeV Si implantation produces a vacancy supersaturated nearsurface region and an interstitial-rich region at the projected ion range. Transient enhanced diffusion (TED) of $\mathrm{Sb}$ in the near surface layer was observed as a result of a $2 \mathrm{MeV} \mathrm{Si}$, $1 \times 10^{16} / \mathrm{cm}^{2}$, implant. A $4 \times$ larger TED of Sb was observed in BESOI than in FZ silicon, demonstrating that the vacancy supersaturation persists longer in BESOI than in FZ. B markers in samples with $\mathrm{MeV}$ Si implant showed a factor of $10 \times$ smaller diffusion relative to markers without the $\mathrm{MeV} \mathrm{Si}^{+}$implant. This data demonstrates that a $2 \mathrm{MeV} \mathrm{Si}^{+}$implant injects vacancies into the near surface region.

\section{INTRODUCTION}

Growing interest in diffusion and TED of dopants has led to a great deal of study of point defects in silicon. However, the focus of most studies has been interstitial type defects, primarily because interstitials have been shown to be responsible for the TED of ion implanted $B$ and $P$ during integrated circuit processing, while much less emphasis has been placed on the study of vacancies. There are several methods for creating interstitial supersaturations of known concentrations in silicon and of analytically quantifying them. For instance, medium-energy ion implantation injects excess interstitials in numbers roughly equal to the total number of implanted ions. ${ }^{1}$ These excess interstitials coalesce into elongated $\{311\}$ defects, which are visible in transmission electron microscopy (TEM) such that the number of interstitials can be measured. TED of $B$ and $P$, which are interstitialcy diffusers whose diffusivity is proportional to the concentration of Si self-interstitials, has been observed as a result of the evaporation of these $\{311\}$ defects. $^{2}$

To fully understand interstitial interactions and dopant diffusion in silicon a better understanding of interstitial-vacancy and dopant-vacancy interactions is also needed. To study vacancy interactions, better methods to prepare and characterize vacancy supersaturations in silicon are required. Thermal nitridation has been shown to create vacancy supersaturations of the order of 3-5 times the equilibrium concentration $\left(\mathrm{C}_{\mathrm{v}}{ }^{\mathrm{eq}}\right)$ of vacancies at temperatures ranging from $800^{\circ}$ to $900^{\circ} \mathrm{C}^{3}$ When compared to the supersaturation of excess interstitials that are created by ion implantation, this supersaturation of vacancies is not very large. Furthermore, the temperature range over which these supersaturations can be achieved is limited to the temperatures at which nitridation is possible. The ability to produce and control larger vacancy supersaturations is desirable in order to improve the sensitivity to detect and measure all the possible vacancy interactions that can take place and their degree of importance. 
High-energy, high-dose self-ion implantation in silicon has been shown to produce large vacancy-rich regions near the silicon surface that can extend a micron or so into the bulk. ${ }^{4,5}$ This can be explained by considering the profiles of interstitial and vacancy point defects created by ion-atom collisions. During ion implantation, both vacancies and interstitials are created in pairs as implanted ions collide with silicon lattice atoms. This results in a distribution of vacancies and interstitials within the implanted layer. The recoil distribution (interstitial distribution) is shifted slightly deeper into the bulk relative to the vacancy distribution, due to the forward momentum of the implanted ion. The spatial separation between the interstitial and vacancy distribution increases with increasing ion energy. In low and medium ion implantation, the spatial separation is small, so during the early stages of annealing the interstitial distribution recombines with the vacancy distribution leaving only excess atoms (interstitial) corresponding to the number of implanted ions. However, for $\mathrm{MeV}$ implantation the spatial separation between the distributions is large enough that after recombination there is a net point defect distribution of excess vacancies over interstitials near the surface and a corresponding region of excess interstitials near the ions range, $R_{p}$. We propose to exploit this vacancy-rich region to control vacancy supersaturation and extend studies of diffusion and point defect interaction to large vacancy concentrations.

There are a number of experiments. that demonstrate the existence of vacancy supersaturations after high-energy self-ion implantation, including positron annihilation spectrometry. ${ }^{4,5}$ In addition, $\{311\}$ defects containing a peak interstitial concentration of approximately $1 \times 10^{18} / \mathrm{cm}^{3}$ have recently been annihilated by superimposing a $2 \mathrm{MeV}$ Si implant with a dose of $1 \times 10^{16} / \mathrm{cm}^{2}$, suggesting that the excess vacancy concentration $\left(\mathrm{C}_{v}^{\mathrm{MeV}}\right)$ produced by this $\mathrm{MeV}$ implant may be as large as $10^{18} / \mathrm{cm}^{3}$. In the same work, the same $\mathrm{MeV}$ implant induced large enhanced diffusion of MBE-grown Sb markers. Since $\mathrm{Sb}$ diffuses primarily by a vacancy mechanism, this is another indicator of a large value of $\mathrm{C}_{\mathrm{v}}^{\mathrm{Mev}} / \mathrm{C}_{\mathrm{v}}{ }^{\text {eq }}$. Other researchers have also used high-energy self-ion implantation to demonstrate a reduction in the TED of implanted boron, consistent with vacancy injection. ${ }^{7,8}$ Further evidence of vacancy supersaturations produced by $\mathrm{MeV}$ Si implantation is shown in Fig. 1. Figure la shows the interstitial type dislocation loops that grow at the original amorphous-crystal interface when a recrystallized a-Si layer was regrown by solid phase epitaxy (SPE) at $600^{\circ} \mathrm{C}$ then post-annealed at $1000^{\circ} \mathrm{C}$ for $20 \mathrm{~min}$. Figure $1 \mathrm{~b}$ shows the same regrown layer with the addition of a $2 \mathrm{MeV} \mathrm{Si}$ implant prior to the $1000^{\circ} \mathrm{C}$ anneal. The $\mathrm{MeV} \mathrm{Si}$ implant resulted in the annihilation of the defects at the original amorphous-crystal interface. Since these defects are interstitial in nature,

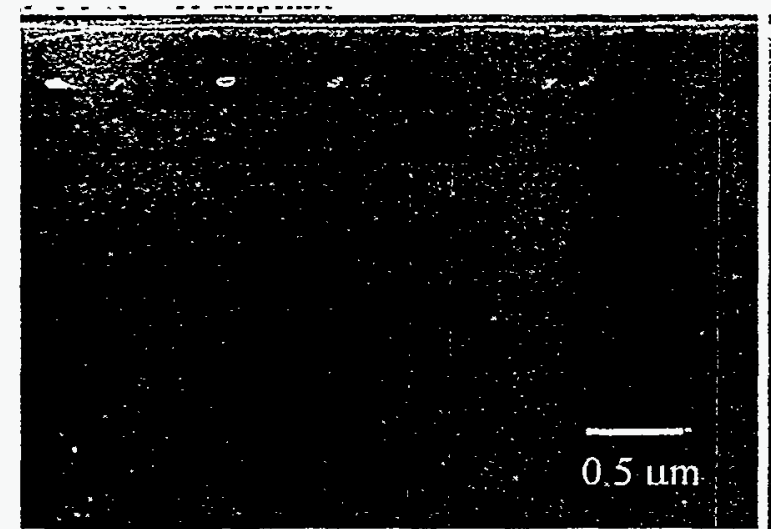

Figure 1a) Interstitial-type defects at the original amorphous crystal interface of a preamorphized layer regrown by SPE and annealed at $1000^{\circ} \mathrm{C}$ for $20 \mathrm{~min}$, in $\mathrm{FZ}-\mathrm{Si}(100)$.

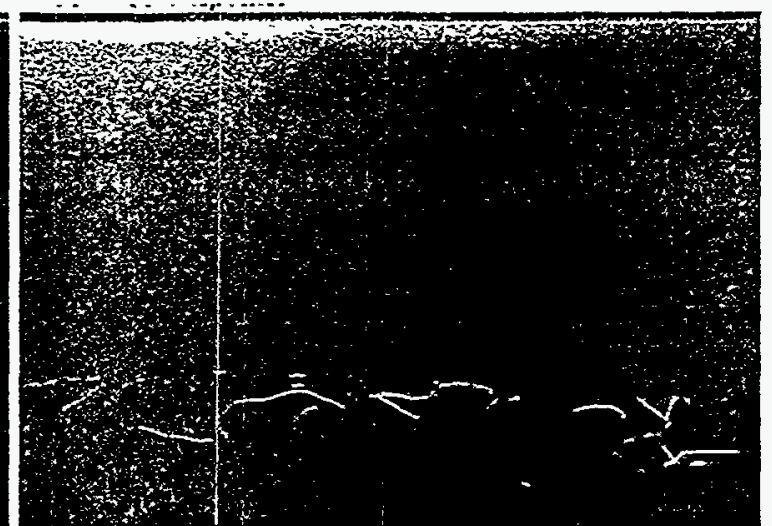

Figure 1b) Same preamorphization and SPE as in a), with the addition of a $2 \mathrm{MeV} \mathrm{Si}{ }^{+}$, $1 \times 10^{16} / \mathrm{cm}^{2}$, implant prior to a $1000^{\circ} \mathrm{C} 20 \mathrm{~min}$ anneal. 
we attribute their disappearance to recombination with the excess vacancies produced from the MeV Si implant.

The aim of this work is to evaluate $\mathrm{MeV}$ Si implantation as a method for injecting a large, and controlled, vacancy supersaturation to study vacancy interactions. The diffusion of Sb and B markers in a vacancy-supersaturated region created by $\mathrm{MeV}$ Si implantation was studied. Since $\mathrm{Sb}$ diffuses by a vacancy mechanism ${ }^{9}$, any enhancement in its diffusivity reflects an enhancement in the vacancy concentration, making the diffusion of $\mathrm{Sb}$ an excellent probe for vacancies. Similarly, B diffuses primarily by an interstitial mechanism; the diffusion of boron is used to detect the possible presence of excess interstitials from the $\mathrm{MeV} \mathrm{Si} \mathrm{implant.} \mathrm{Using} \mathrm{Sb}$ and $\mathrm{B}$ markers in this complementary fashion allows us to monitor both vacancy and interstitials supersaturations, and potentially to detect vacancy-interstitial interaction.

\section{EXPERIMENT}

Diffusion markers were prepared by a sequence of amorphizing implants followed by dopant implantation and SPE as follows. Wafers were preamophized with a dual Si ion implant of 70 and $140 \mathrm{keV}$, both to a dose of $6 \times 10^{14} / \mathrm{cm}^{2}$ at $77 \mathrm{~K}$. Ion channeling measurements confirmed that the amorphous layer was continuous to the surface and $3000^{\circ} \AA$ thick. Diffusion markers of $\mathrm{Sb},\left(290 \mathrm{keV} 1.8 \times 10^{13} / \mathrm{cm}^{2}\right)$ or $\mathrm{B}\left(30 \mathrm{keV} 1.8 \times 10^{13} / \mathrm{cm}^{2}\right)$, were then implanted into the amorphous layer. The implant energies were chosen to place the markers and the damage from the implant well within the amorphous region. These doses produce a peak concentration of $2 \times 10^{18}$ atoms $/ \mathrm{cm}^{3}$ for both $\mathrm{Sb}$ and $\mathrm{B}$. The substrates were then regrown by SPE at $600^{\circ} \mathrm{C}$ for 1 hour in $1 \mathrm{~atm}$ of $\operatorname{Ar}\left(4 \% \mathrm{H}_{2}\right)$. These preamorphization and SPE steps were performed to reduce the channeling tail and to place the dopants on substitutional sites with minimal diffusion. A portion of each sample was then implanted with $2 \mathrm{MeV} \mathrm{Si}$ ions to a dose of $1 \times 10^{16} / \mathrm{cm}^{2}$. This implant was done at an elevated temperature of $300^{\circ} \mathrm{C}$ to prevent amorphization and promote local recombination of defects. The portions of the samples that were not implanted with $2 \mathrm{MeV}$ $\mathrm{Si}^{+}$ions will be referred to as reference samples. The marker samples were then annealed at $1000^{\circ} \mathrm{C}$ for $20 \mathrm{~min}$ or at $800^{\circ} \mathrm{C}$ for $15 \mathrm{~min}$ in $\mathrm{Ar}\left(4 \% \mathrm{H}_{2}\right)$. Sb and $\mathrm{B}$ concentration profiles were analyzed by secondary-ion mass spectrometry (SIMS). Diffusivities were measured by fitting the diffused profiles with a diffusion simulator.

These experiments were performed in BESOI material as well as in FZ silicon. The buried oxide in the BESOI is intended to be a barrier to the possible back diffusion of silicon interstitials from $R_{p}$ of the $\mathrm{MeV}$ implant. In a recent experiment, enhanced diffusion of $\mathrm{MBE}-$ grown B markers was observed as a result of a MeV Si implantation ${ }^{6}$, suggesting that the deep interstitials may influence near surface diffusion unless some such barrier is provided. Interstitials have been shown to have a very small diffusivity in $\mathrm{SiO}_{2},{ }^{10}$ so the buried oxide in the BESOI should act as an effective barrier. In addition, positron annihilation spectroscopy data has shown that the vacancy supersaturations created by $\mathrm{MeV}$ implantation exist for longer times and at higher temperatures in BESOI than they do in FZ or Czochralski $(\mathrm{Cz})$ silicon. ${ }^{11}$ The BESOI substrate consisted of $5000 \AA \mathrm{Cz}-\mathrm{Si}(100)$ on a $4500 \AA$ oxide. The energy of the $\mathrm{MeV} \mathrm{Si}$ implant was chosen to put $\mathrm{R}_{\mathrm{p}}(\sim 2 \mu \mathrm{m})$ well beyond the buried oxide in the BESOI.

\section{RESULTS}

Figure 2 shows SIMS concentration profiles for Sb markers in FZ-Si(100). The initial profile of the regrown $\mathrm{Sb}$ marker is included in the figure. The reference Sb marker annealed at 


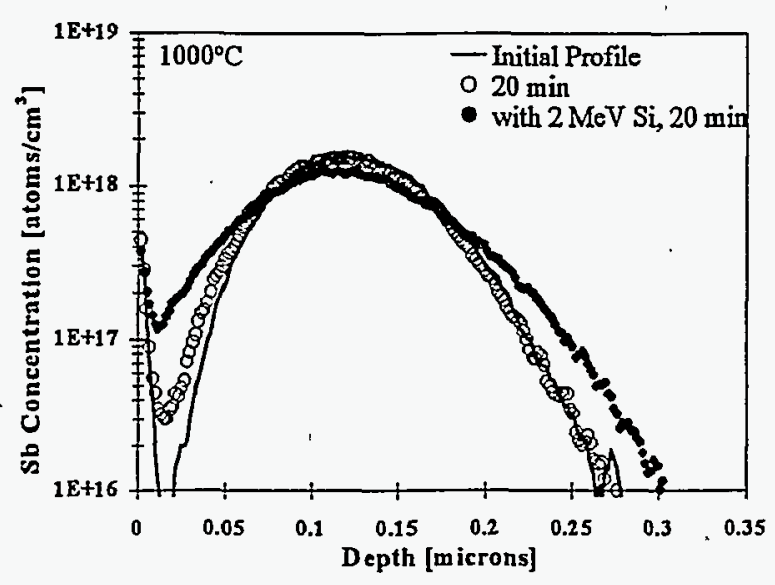

Figure 2. $\mathrm{Sb}$ concentration profile in FZ$\mathrm{Si}(100)$ of initial $\mathrm{Sb}$ marker, annealed at $1000^{\circ} \mathrm{C}$ for $20 \mathrm{~min}$, and implanted with $\mathrm{MeV}$ $\mathrm{Si}^{+}$prior to $20 \mathrm{~min}$ anneal at $1000^{\circ} \mathrm{C}$.

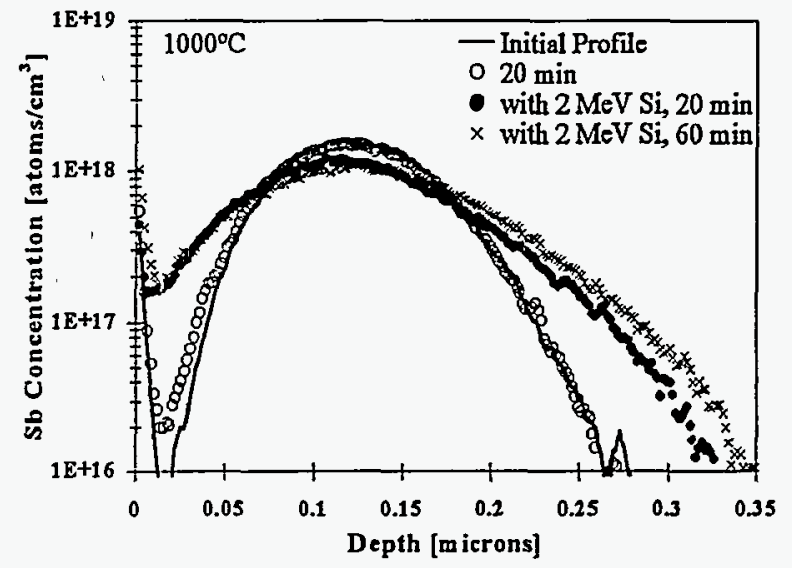

Figure 3. Sb concentration profile in $\mathrm{BESOI}$ of initial $\mathrm{Sb}$ marker, annealed at $1000^{\circ} \mathrm{C}$ for 20 min, implanted with $\mathrm{MeV} \mathrm{Si}{ }^{+}$prior to $20 \mathrm{~min}$ anneal at $1000^{\circ} \mathrm{C}$, and implanted with $\mathrm{MeV} \mathrm{Si}^{+}$ prior to $60 \mathrm{~min}$ anneal at $1000^{\circ} \mathrm{C}$.

$1000^{\circ} \mathrm{C}$ for $20 \mathrm{~min}$ shows hardly any diffusion. Its time averaged diffusivity, $\left\langle\mathrm{D}_{\mathrm{Sb}}{ }^{\mathrm{Ref}}\right\rangle$, was found to be $2.3 \times 10^{-16} \mathrm{~cm}^{2} / \mathrm{s}\left(+0.3 \times 10^{-16},-2 \times 10^{-16}\right)$. The marker implanted with $\mathrm{MeV}$ Si ions prior to annealing at $1000^{\circ} \mathrm{C}$ for $20 \mathrm{~min}$ diffused much more than the $\mathrm{Sb}$ reference marker. Its time-averaged diffusivity, $\left\langle\mathrm{D}_{\mathrm{sb}}{ }^{\mathrm{MeV}}\right\rangle$, was found to be $4.5 \times 10^{-15} \mathrm{~cm}^{2} / \mathrm{s}\left(+/-0.4 \times 10^{-15}\right)$. Therefore, there is at least a $20 \times$ enhancement in the average $\mathrm{Sb}$ diffusivity, due to the $\mathrm{MeV}$ Si implant in $\mathrm{FZ}$ silicon. Since $\mathrm{Sb}$ is a vacancy diffuser whose diffusivity is proportional to the vacancy concentration, we conclude that there was at least a $20 x$ enhancement in the vacancy concentration as a result of the $\mathrm{MeV} \mathrm{Si}$ implant when compared to the reference Sb marker: $\left\langle\mathrm{C}_{\mathrm{v}}{ }^{\mathrm{MeV}}>/<\mathrm{C}_{\mathrm{v}}{ }^{\mathrm{Ref}}>\geq 20\right.$.

Figure 3 shows the corresponding $\mathrm{Sb}$ concentration profiles in BESOI. Again, the reference $\mathrm{Sb}$ markers show very little diffusion: $\left\langle\mathrm{D}_{\mathrm{Sb}}^{\mathrm{Ref}}\right\rangle=2.3 \times 10^{-16} \mathrm{~cm}^{2} / \mathrm{s}\left(+0.3 \times 10^{-16},-2 \times 10^{-16}\right)$. Similar to the $\mathrm{FZ}$ case, the $\mathrm{Sb}$ marker implanted with $2 \mathrm{MeV}$ Si ions prior to annealing diffused much more than the reference sample: $\left\langle\mathrm{D}_{\mathrm{Sb}} \mathrm{MeV}^{\mathrm{M}}\right\rangle=8.6 \times 10^{-15} \mathrm{~cm}^{2} / \mathrm{s}\left(+/-0.6 \times 10^{-15}\right)$ in BESOI. So, there was at least a $37 \times$ enhancement in the diffusivity of $\mathrm{Sb}$ in BESOI, implying that $\left\langle\mathrm{C}_{\mathrm{v}}{ }^{\mathrm{MeV}}>/<\mathrm{C}_{\mathrm{v}}{ }^{\mathrm{Ref}}\right\rangle \geq 37$. The enhancement in $\mathrm{Sb}$ diffusivity due to the $\mathrm{MeV} \mathrm{Si}{ }^{+}$implantation in the BESOI is larger than it is in FZ by almost $2 x$, suggesting that in the BESOI substrate a larger vacancy supersaturation persists over the duration of the anneal. We attribute this effect to the buried oxide in the BESOI, which can act as a barrier to the back diffusion of excess interstitials that form at the range of the $\mathrm{MeV}$ implant.

Also included in Fig. 3 is an Sb marker profile after implantation with $2 \mathrm{MeV}$ Si ions and annealing at $1000^{\circ} \mathrm{C}$ for $60 \mathrm{~min}$. Comparing the profiles in Fig. 3, we see that the diffusion was larger in the first $20 \mathrm{~min}$ of the anneal than it was for the next $40 \mathrm{~min}$. By simulating the evolution of the $20 \mathrm{~min}$ profile into the $60 \mathrm{~min}$ profile, we obtain an average diffusivity of $2.2 \times 10^{-15} \mathrm{~cm}^{2} / \mathrm{s}$. This is 4 times smaller than the average diffusivity over the first $20 \mathrm{~min}$, clearly indicating that $\left\langle\mathrm{C}_{\mathrm{v}}{ }^{\mathrm{MeV}}\right\rangle$ is decreasing over this time scale and that the diffusion enhancement is transient. This result confirms the first observation of TED of $\mathrm{Sb}$ as a result of ion implantation (Ref 6) and extends that result to higher temperatures and to non-MBE grown samples. 


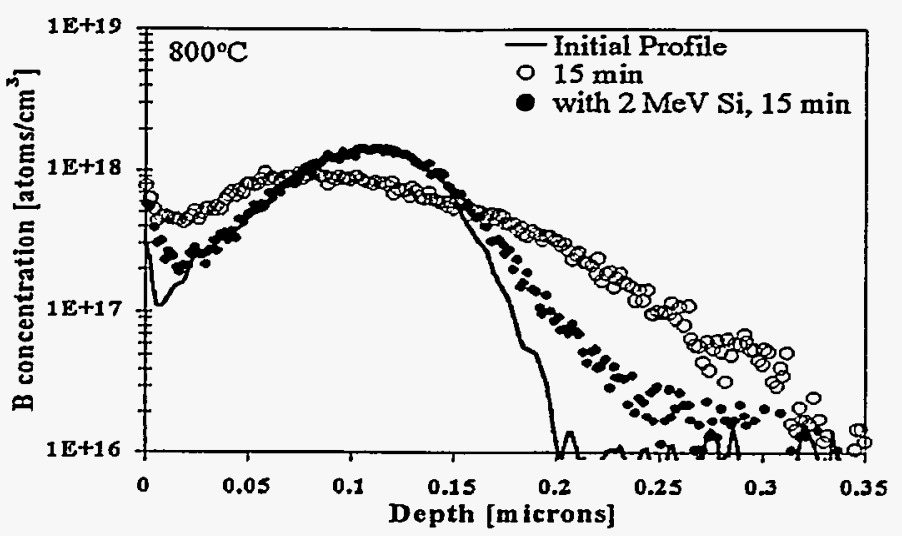

Figure 4. B concentration profile in FZ-Si(100) of initial B marker, B marker annealed at $800^{\circ} \mathrm{C}$ for $15 \mathrm{~min}$, and $\mathrm{B}$ marker implanted with $\mathrm{MeV}$ $\mathrm{Si}^{+}$prior to $15 \mathrm{~min}$ anneal at $800^{\circ} \mathrm{C}$.

We have also measured the diffusion of $B$ markers in order to determine whether the $\mathrm{MeV}$ implant is also injecting interstitials in the near surface. Concentration profiles for $\mathrm{B}$ markers with and without a $2 \mathrm{MeV} \mathrm{Si}^{+}$implant annealed at $800^{\circ} \mathrm{C}$ for $15 \mathrm{~min}$ are shown in Fig. 4. In contrast to the case of $\mathrm{Sb}$, we see that the reference $\mathrm{B}$ marker has diffused much more than the $\mathrm{B}$ marker implanted with MeV Si ions prior to annealing. We obtain $\left\langle D_{B}{ }^{R e f}\right\rangle=2.2 \times 10^{-14} \mathrm{~cm}^{2} / \mathrm{s}$ and $\left\langle\mathrm{D}_{\mathrm{B}}{ }^{\mathrm{MeV}}>=2.2 \times 10^{-15} \mathrm{~cm}^{2} / \mathrm{s}\left(+/-0.3 \times 10^{-14}\right)\right.$. Comparing these values to intrinsic boron diffusion at $800^{\circ} \mathrm{C}, 4.5 \times 10^{-17} \mathrm{~cm}^{2} / \mathrm{s}$, we see that for the reference $\mathrm{B}$ marker there is approximately a 500x enhancement, while for the $\mathrm{MeV} \mathrm{Si} \mathrm{implanted} \mathrm{B} \mathrm{marker} \mathrm{the} \mathrm{enhancement} \mathrm{is} \mathrm{only}$ approximately $50 x$. We attribute these enhancements in B diffusivity to residual interstitials remaining at the position of the original amorphous-crystal interface after SPE regrowth (see Fig. 1). Preamorphization and subsequent SPE regrowth have previously been shown to enhance the diffusion of boron for amorphization conditions similar to ours. ${ }^{12}$ Nevertheless, the $2 \mathrm{MeV} \mathrm{Si}$ implant has resulted in a reduction in the diffusion of the $\mathrm{B}$ marker as compared to the reference $\mathrm{B}$ marker: $\left\langle\mathrm{D}_{\mathrm{B}}{ }^{\mathrm{MeV}}\right\rangle \mid\left\langle\mathrm{D}_{\mathrm{B}}{ }^{\mathrm{Ref}}\right\rangle=0.1$. This reduction is attributed to the excess vacancies produced by the $\mathrm{MeV}$ implant and their recombination with the SPE-induced interstitials and suggests that if there is any interstitial injection from the $\mathrm{MeV}$ implant at the depth of the B profile, it is vastly. overwhelmed by the vacancy injection.

$\mathrm{B}$ markers with and without $\mathrm{MeV} \mathrm{Si}$ implantation have also been annealed at $1000^{\circ} \mathrm{C}$ for $20 \mathrm{~min}$. At that temperature, we observe very little enhancement relative to equilibrium $\mathrm{B}$ diffusion in the absence of the $\mathrm{MeV}$ implant, and evidence of a slight reduction following $\mathrm{MeV}$ implantation. So we conclude that at this temperature, vacancy injection dominates over interstitial injection at the marker depth.

It should be mentioned that the measured diffusivity for the reference $\mathrm{Sb}$ markers annealed at $1000^{\circ} \mathrm{C}$ for $20 \mathrm{~min}$ was reduced by $10 \mathrm{x}$ as compared to the intrinsic diffusivity of $\mathrm{Sb}$ at $1000^{\circ} \mathrm{C}: \mathrm{D}_{\mathrm{Sb}}{ }^{\mathrm{Ref}}=2.3 \times 10^{-16} \mathrm{~cm}^{2} / \mathrm{s}$ and $\mathrm{D}_{\mathrm{Sb}}{ }^{\mathrm{eq}}=2.3 \times 10^{-15} \mathrm{~cm}^{2} / \mathrm{s}$ at $1000^{\circ} \mathrm{C}$. We attribute this to residual interstitials from the SPE trapping or recombining with vacancies in the near surface region. Since all of the $\mathrm{Sb}$ markers were prepared under the same conditions, and we are directly comparing the effects of $\mathrm{MeV}$ implanted markers to markers that did not have the $\mathrm{MeV}$ implant, our conclusions regarding diffusion enhancements and vacancy injection due to $\mathrm{MeV}$ implantation are still valid.

\section{CONCLUSIONS}

The diffusion of $\mathrm{Sb}$ and $\mathrm{B}$ markers has been measured in regions of vacancy supersaturation created by $2 \mathrm{MeV}$ Si ion implantation. Sb diffusion was studied as a probe for vacancies, and B diffusion was studied as a probe for interstitials. TED of Sb was observed at 
$1000^{\circ} \mathrm{C}$ in markers implanted with $\mathrm{MeV} \mathrm{Si}$ ions relative to unimplanted markers. The enhancement decreases for longer times at $1000^{\circ} \mathrm{C}$, indicating that the concentration of vacancies was decreasing with time. Based on these measurements we estimate that the $2 \mathrm{MeV} \mathrm{Si}$, $1 \times 10^{16} / \mathrm{cm}^{2}$, produces a time averaged vacancy supersaturation, $\left\langle\mathrm{C}_{\mathrm{v}}{ }^{\mathrm{MeV}}>/\left\langle\mathrm{C}_{\mathrm{v}}{ }^{\text {Ref }}\right\rangle\right.$, of at least $37 \times$ in the first $20 \mathrm{~min}$ of the $1000^{\circ} \mathrm{C}$ anneal in BESOI, that decreased to less than $10 \times$ by $60 \mathrm{~min}$. Such large vacancy supersaturations have not been observed previously at this temperature. At the same time, the $\mathrm{MeV} \mathrm{Si}{ }^{+}$implant did not contribute to the enhancement of $\mathrm{B}$ markers. In fact, at $800^{\circ} \mathrm{C}$, the $\mathrm{MeV}$ implant dramatically reduced the $\mathrm{B}$ diffusion, confirming that the excess vacancies produced by the $\mathrm{MeV}$ Si implant can reduce the concentration of residual interstitials in the near surface region. We believe that $\mathrm{MeV} \mathrm{Si}$ implantation can be used as a "tool" for injecting a controlled concentration of excess vacancies. Such methods may ultimately enable in rependent control of interstitial and vacancy concentrations, making it possible to design experiments that could measure interstitial-vacancy recombination rates, unambiguously determine diffusion mechanisms for dopants, and determine equilibrium concentrations of point defects.

\section{ACKNOWLEGMENTS.}

Research at Oak Ridge National Laboratory was sponsored by the U.S. Department of Energy, Office of Energy Research, Laboratory Technology Division and the Division of Materials Sciences under contract DE-AC05-960R22464 with Lockheed Martin Energy Research Corp. I' would like to acknowledge support from Oak Ridge Associated Universities funded under contract \# DE-ACO5-760R00033 with the U.S. Department of Energy.

\section{REFERENCES}

${ }^{1}$ D. J. Eaglesham, P. A. Stolk, H. -J. Gossmann, T. E. Haynes, and J. M. Poate, Nucl. Instrum. Meth. Phys. Res. B 106, 191 (1995).

${ }^{2}$ D. J. Eaglesham, P. A. Stolk, H. -J. Gossmann, and J. M. Poate, Appl. Phys. Lett. 65, 2305 (1994).

${ }^{3}$ T. K. Mogi, Michael O. Thompson, H. -J. Gossmann, J. M. Poate, and H. S. Luftman, Appl. Phys. Lett. 69 (9), 1273 (1996).

${ }^{4}$ B. Nielsen, O. W. Holland, T. C. Lueng, and K. G. Lynn, J. Appl. Phys. 74, 1636 (1993).

${ }^{5}$ O. W. Holland, B. Nielsen, and D. S. Zhou, J. Electron. Matter. 25, 99 (1996)

${ }^{6}$ D. J. Eaglesham, T. E. Haynes, H. -J. Gossmann, D. C. Jacobson, P. A. Stolk, and J. M. Poate, submitted to Appl. Phys. Lett.

${ }^{7}$ V. Raineri, R. J. Schreutekamp, F. W. Saris, K. T. F. Janssen, and R. E. Kaim, Appl. Phys. Lett. 58 (9), 922 (1991).

8 K. Kyllesbech Larsen, V. Privitera, S. Coffa, F. Priolo, C. Spinella, M. Saggio, and

S. U. Compisano, 'Nucl. Instrum. Meth. Phys. Res. B 112, 139 (1996).

${ }^{9}$ R. B. Fair, M. L. Manda, and J. J. Wortman, J. Mater. Res. 1, 705 (1986).

${ }^{10}$ G. K. Celler and L. E. Trimble, Appl. Phys. Lett. 54 (15), 1427 (1989)

${ }^{11}$ B. Nielsen, unpublished data.

12 K. S. Jones, R. G. Elliman, M. M. Petravac, and P. Kringhoj, Appl. Phys. Lett. 68 (22), 3111 (1996). 